Original article

\title{
Supplementing in vitro embryo production media by NPPC and sildenafil affect the cytoplasmic lipid content and gene expression of bovine cumulus- oocyte complexes and embryos
}

\author{
Ramon Cesar Botigelli ${ }^{\mathrm{a}, \mathrm{b}, *}$, Eduardo Montanari Razza ${ }^{\mathrm{a}}$, Elisa Mariano Pioltine ${ }^{\mathrm{a}}$, \\ Patricia Kubo Fontes ${ }^{\mathrm{a}}$, Kátia Regina Lancellotti Schwarz ${ }^{\mathrm{b}}$, Cláudia Lima Verde Leal ${ }^{\mathrm{b}}$, \\ Marcelo Fábio Gouveia Nogueira ${ }^{\mathrm{a}, \mathrm{c}}$
}

a São Paulo State University (UNESP), Institute of Biosciences, Department of pharmacology, Botucatu, São Paulo, 18618-689, Brazil

${ }^{\mathrm{b}}$ University of São Paulo (USP), Faculty of Animal Science and Food Engineering, Department of Veterinary Medicine, Pirassununga, São Paulo, 13635-900, Brazil

' São Paulo State University (UNESP), School of Sciences, Humanities and Languages, Department of Biological Science, Assis, São Paulo, 19806-900, Brazil

\section{A R T I C L E I N F O}

\section{Keywords:}

Lipid content

Gene expression

Cumulus-oocyte complexes

Embryos

\begin{abstract}
A B S T R A C T
In our study, we added natriuretic peptide type C (NPPC) and/or sildenafil during in vitro maturation (IVM) of bovine cumulus-oocyte complexes (COCs) followed by in vitro culture (IVC) of embryos with or without sildenafil. We evaluated the effects on the lipid content (LC) of oocytes and embryos and also verified the expression of 96 transcripts related to competence in matured COCs and 96 transcripts related to embryo quality in blastocysts. After IVM, LC was decreased in oocytes by NPPC while sildenafil did not affect LC in oocytes. The genes involved in lipid metabolism and lipid accumulation (DGAT1, PLIN2and PLIN3) were not affected in COCs after treatment during IVM, although the expression of PTX3 (a cumulus cells expansion biomarker) was increased and the hatched blastocyst rate was increased by NPPC during IVM. During IVM, sildenafil increased the mRNA relative abundance of HSF1 and PAF1 and decreased REST in blastocysts. The use of sildenafil in IVC increased the LC of blastocysts. The mRNA abundance in blastocysts produced during IVC with sildenafil was changed for ATF4, XBP1, DNMT3A, DNMT3B, COX2, and SOX2. Although NPPC reduced the LC of oocytes after IVM and upregulated markers for cumulus expansion, embryo production was not affected and the produced blastocysts were able to regain their LC after IVC. Finally, the use of sildenafil during IVC increased the cytoplasmic LC of embryos but did not affect embryo quality, as measured by analysis of 96 transcripts related to embryo quality.
\end{abstract}

\section{Introduction}

The in vitro maturation (IVM) of mammalian oocytes is a crucial tool for investigating basic and applied aspects of assisted reproductive technology (ART), such as developmental biology, stem cell development, in vitro production (IVP) of embryos, cloning, and embryology [1]. However, the efficiency of IVM is still low when compared to in vivo maturation, limiting its application [2]. This inefficiency is probably caused by a drastic decrease in cyclic adenosine monophosphate (cAMP) concentration within the oocyte after the removal of cumulusoocyte complexes (COC) from the follicular environment, causing the spontaneous resumption of meiosis during ART procedures [3,4].

Many pharmacological approaches are used in IVM to maintain meiotic arrest or delay spontaneous resumption of meiosis. One common approach consists of the use of cyclic nucleotide (cAMP and
cGMP) modulators, such as dbcAMP [5] and 8-bromo-cAMP [6]; stimulators of adenylate cyclase, such as forskolin [7] and iAC [4]; and cGMP modulators, such as SNP $[8,13]$ and SNAP [9], for modifying IVM and improving developmental competence.

Recent studies have indicated the influence of C-type natriuretic peptide (NPPC) on meiosis resumption in various species: mice [10], pig [11], cattle [12], and goat [13]. NPPC is synthetized by granulosa cells and binds to natriuretic peptide receptor 2 (NPR2) mostly present in cumulus cells. NPR2 activation induces the synthesis of cyclic guanosine monophosphate (cGMP), which is transferred via gap junctions from cumulus cells to the oocyte. There, cGMP has inhibitory action over phosphodiesterase 3A (PDE3A), maintaining high concentrations of cAMP in the oocyte and sustaining meiosis arrest [10].

Cyclic GMP synthesis is stimulated via different pathways, including through nitric oxide, natriuretic peptides (NPPA, NPPB, and NPPC),

\footnotetext{
* Corresponding author at: São Paulo State University (UNESP), Institute of Biosciences, Department of pharmacology, Botucatu, São Paulo, 18618-689, Brazil.

E-mail address: ramonbotigelli@usp.br (R.C. Botigelli).
} 
guanylins, uroguanylins, and guanylyl cyclase activating proteins (GCAPs), which catalyze conversion of guanosine triphosphate (GTP) into cGMP and pyrophosphate [14]. The concentration of cGMP is controlled by the balance between its synthesis and degradation, which is carried out by the PDEs themselves [15]. Sildenafil is a pharmacologic inhibitor of PDE5, which is the enzyme responsible for the hydrolysis of cGMP levels, decreasing its levels, and affecting the balance between cGMP and cAMP, which are involved in spontaneous meiosis resumption [16]. Additionally, cGMP activates cGMP-dependent protein kinase (PKG) [15]. Members of the PKG family (PKG I and II) act on specific substrates in the cells, leading to a series of metabolic effects. The signaling pathway activated by cGMP/PKG may trigger lipolytic action through phosphorylation of perilipin and lipases $[17,18]$.

Lipids have been intensively studied in many mammalian cells. The most abundant cytoplasmic lipids in bovine oocytes and embryos are triacylglycerides (TG) [19], which are stored in lipid droplets. Intracellular lipids represent an important source of energy for oocytes and preimplantation embryos [19]. Recently, Schwarz and collaborators [20] described the influences of cGMP levels on lipid content in oocytes and embryos and on transcripts of energy metabolism. However, few studies have been conducted evaluating the effects of cGMP modulators on lipid metabolism and the few studies conducted are inconclusive [20,21]. Thus, several approaches focus on the reduction of lipid accumulation in IVP embryos by modifications of the culture media aimed at improvement in embryonic performance and quality [22-24], including enhancing their cryosurvival [22,24,25].

In this way, the manipulation of cGMP levels with NPPC (synthesized by its binding to NPR2) and sildenafil (inhibitor of the cGMP hydrolyzing enzyme PDE5A) may affect lipid metabolism in bovine COCs and embryos. The aim of this study was to determine the influence of NPPC and/or sildenafil, during IVM of bovine COCs, on lipid content, expression of markers of oocyte quality, and competence for embryonic development in cumulus cells, as well as genes involved in metabolism and the maturation process. In addition, the effects of these IVM treatments, which are used for the IVP of embryos, were assessed by the addition of sildenafil during embryo culture and measuring embryo production, lipid content, and the expression of embryo quality-related genes in bovine blastocysts.

\section{Material and methods}

\subsection{Media and chemicals}

All chemicals used in this study were purchased from Sigma-Aldrich (USA) unless otherwise indicated.

\subsection{Oocyte collection}

Ovaries from Bos Indicus cows were collected at a commercial abattoir immediately after slaughter and transported in sterile saline solution at $30^{\circ} \mathrm{C}$. In the laboratory, 3 to $8 \mathrm{~mm}$ follicles were aspirated with an 18 "G" needle attached to a disposable $10 \mathrm{~mL}$ syringe. The aspirated follicular fluid was placed in $15 \mathrm{~mL}$ conical tubes and maintained for $5 \mathrm{~min}$ for sedimentation. The upper portion of the liquid was removed and the remaining portion was then transferred to a Petri dish $(100 \times 15 \mathrm{~mm})$ under a stereomicroscope for selection of grade I and II cumulus-oocyte complexes. COCs were classified as grade I when presenting five or more layers of cumulus cells and homogeneous cytoplasm and grade II with 2-4 layers and homogeneous cytoplasm [26].

\subsection{Experimental design}

2.3.1. Experiment 1: the effects of NPPC and/or sildenafil on lipid content and gene expression in COCs after IVM

The COCs were divided into four groups during IVM: control (without supplementation), NPPC (supplemented with $100 \mathrm{nM}$ NPPC,
[12]), sildenafil (supplemented with $10 \mu \mathrm{M}$ sildenafil, [27]), and NPPC plus sildenafil (supplemented with $100 \mathrm{nM}$ NPPC and $10 \mu \mathrm{M}$ sildenafil). After $24 \mathrm{~h}$ of IVM, 298 denuded oocytes were evaluated for the determination of lipid content using the fluorescent probe Nile Red and triplicate pools, each with 10 COCs, were evaluated by Real-time PCR (qPCR) using a Fluidigm Biomark ${ }^{\mathrm{TM}}$ HD system for relative gene expression of 96 targets related to oocyte competence and pathways involved in maturation processes.

\subsubsection{Experiment 2: the effects of NPPC and/or sildenafil during IVM on} lipid content and gene expression of 96 targets related to embryo quality in blastocysts

After IVM, COCs were in vitro fertilized and the embryos were in vitro cultured. The rates of embryo production were assessed on day 7 (D7). The produced 169 blastocysts or expanded blastocysts (D7, Class I and II) were analyzed for lipid content with the fluorescent probe Nile Red and quadruplicate pools with 5 blastocysts each (D7, Class I and II) were evaluated by Real-time PCR (qPCR) using a Fluidigm Biomark ${ }^{\mathrm{TM}}$ HD system regarding relative gene expression of 96 targets related to embryo quality.

2.3.3. Experiment 3: the influence of sildenafil during IVC on lipid content and gene expression of 96 targets related to embryo quality in blastocysts produced from COCs maturated with NPPC and/or sildenafil during IVM

After IVF, the embryos were cultured with $10 \mu \mathrm{M}$ sildenafil and rates of embryo production were assessed at D5 and D7. The 210 blastocysts or expanded blastocysts produced (D7, Class I and II) were analyzed for lipid content and quadruplicate pools with 5 blastocysts each (D7, Class I and II) were analyzed by Real-time PCR (qPCR) using a Fluidigm Biomark $^{\mathrm{TM}} \mathrm{HD}$ system for relative gene expression of 96 targets related to embryo quality.

\subsection{In vitro maturation}

For in vitro maturation (IVM), the selected COCs were cultured in maturation medium (TCM199 with $20 \mathrm{mM}$ bicarbonate) containing $0.2 \mathrm{mM}$ sodium pyruvate, $0.1 \mathrm{IU} / \mathrm{mL}$ recombinant human FSH (Merck Serono; Bali, Italy), $5 \mathrm{mg} / \mathrm{mL}$ bovine serum albumin-fatty acid free and $10 \mu \mathrm{g} / \mathrm{mL}$ gentamicin. Groups of 50 COCs were matured in $500 \mu \mathrm{L}$ of maturation medium under silicone oil (Quimesp Química, Guarulhos, SP, BRA), in four-well dishes (NUNC, Thermo Fisher Scientific, Rochester, NY, USA), and incubated at $38.5{ }^{\circ} \mathrm{C}$ and $5 \% \mathrm{CO} 2$ in air and maximum humidity for $24 \mathrm{~h}$.

\subsection{In vitro embryo production}

For embryo production in vitro, the matured oocytes were transferred to drops (25 oocytes per drop) containing $100 \mu \mathrm{L}$ fertilization medium and covered with mineral oil in Petri dish $(60 \times 15 \mathrm{~mm})$. Oocytes were subjected to in vitro fertilization (IVF) using frozen semen from the same bull of proven fertility. Spermatozoa were selected using the Percoll method, and the concentration was adjusted to $1 \times 10^{6}$ sperm cells/mL [27]. Fertilization was performed in droplets of Tyrode's Albumin-Lactate-Pyruvate (TALP) medium [28] under mineral oil, supplemented with $5 \mathrm{mg} / \mathrm{mL}$ BSA, $0.2 \mathrm{mM} / \mathrm{mL}$ pyruvate, $20 \mu \mathrm{g} / \mathrm{mL}$ heparin, $18 \mu \mathrm{M} / \mathrm{mL}$ penicillamine, $10 \mu \mathrm{M} / \mathrm{mL}$ hypotaurine, $1.8 \mu \mathrm{M} / \mathrm{mL}$ epinephrine, $100 \mu \mathrm{g} / \mathrm{mL}$ streptomycin sulfate and $100 \mathrm{IU} / \mathrm{mL}$ penicillin (Gibco). Oocytes and spermatozoa were co-incubated at $38.5{ }^{\circ} \mathrm{C}$ and $5 \%$ $\mathrm{CO} 2$ in air and maximum humidity for $18-18: 30 \mathrm{~h}$. The day of fertilization was defined as Day 0 (D0). Presumptive zygotes were denuded by vortexing for $2 \mathrm{~min}$ in slow speed, afterwards the presumptive zygotes were transferred to Petri dishes and placed in $90 \mu \mathrm{L}$ droplets of culture medium (10-15 presumptive zygotes per drop), covered with mineral oil. The dishes were then placed in plastic bags containing a gas mixture of 5\% O2, 5\% CO2, and 90\% N2 (White Martins, São Paulo, SP, Brazil) and incubated at $38.5^{\circ} \mathrm{C}$ and maximum humidity. The culture 
medium was synthetic oviduct fluid with amino acids (SOFaa) [29] supplemented with $2.7 \mathrm{mM} / \mathrm{mL}$ myo-inositol, $0.2 \mathrm{mM} / \mathrm{mL}$ pyruvate, $2.5 \%$ fetal calf serum (FCS; v/v), $5 \mathrm{mg} / \mathrm{mL}$ BSA (fatty acid-free), $100 \mu \mathrm{g} / \mathrm{mL}$ streptomycin sulfate and $100 \mathrm{IU} / \mathrm{mL}$ penicillin. After $120 \mathrm{~h}$ (D5) of culture, cleavage was checked and the culture medium was partially replaced with $50 \mu \mathrm{L}$ of fresh medium supplemented with $0.09 \mathrm{~g} / \mathrm{mL}$ glucose. The embryos remained in culture until Day 7 (D7), when blastocyst rates were calculated relative to total COCs matured in each treatment. Additionally, we evaluated the effect of sildenafil ( $10 \mu \mathrm{M}$ sildenafil) supplementation during in vitro culture on the lipid content of blastocysts and expanded blastocysts, and on the expression of genes related to blastocyst quality.

\subsection{Determination of lipid content with the fluorescent probe Nile red}

The denuded oocytes and class I and II embryos (blastocysts and expanded blastocysts) (classified according to the International Embryo Transfer Society-IETS, [30]) were submitted to the same protocol for lipid determination. Cumulus cells were removed from COCs using 0.3 IU hyaluronidase in PBS plus $0.1 \%$ polyvinylpyrrolidone (PBS + PVP) and after washing them in PBS + PVP, oocytes and embryos were fixed and permeabilized in $4 \%$ paraformaldehyde with $0.5 \%$ Triton X-100 solution in PBS + PVP for $20 \mathrm{~min}$ at room temperature and then washed $3 \mathrm{x}$ in PBS + PVP. Oocytes and embryos were stained with $1 \mu \mathrm{g} /$ mL Nile Red (Molecular Probes, Invitrogen, Eugene, USA) in PBS + PVP for $30 \mathrm{~min}$, protected from light and at room temperature. After this period, the oocytes and embryos were washed $3 \mathrm{x}$ in PBS + PVP and transferred to a glass slide (12 oocytes or embryos/slide) containing $5 \mu \mathrm{L}$ Vectashield mounting medium (Brunschwig Chemie, Amsterdam, Netherlands), which was carefully covered with a coverslip. The fluorescence of Nile Red was evaluated under an epifluorescence microscope (Leica DM 4500B; excitation 515-560 nm and emission greater than $590 \mathrm{~nm}$ ) with fast resolution [31]. The photographs of stained oocytes or embryos ( $20 \times$ magnification) were taken at $80 \mathrm{~ms}$ exposure and the fluorescence intensity (FI) was measured using ImageJ software. The lipid content is presented as mean of the fluorescence intensity in arbitrary units [32].

\subsection{RNA extraction and reverse transcription}

Total RNA was extracted from two sources: a pool of 10 cumulusoocyte complexes and a pool of 5 class I expanded blastocysts. RNA extraction was performed using the RNeasy Micro Kit (QIAGEN, Hilden, Germany) and PicoPure RNA isolation kit (Applied Bio-systems, Foster City, CA, USA), respectively, according to the manufacturer's instructions. Genomic DNA contamination was removed by performing DNA digestion using RNase-free DNase (Qiagen, Mississauga, ON, Canada). RNA of COCs and embryos was eluted in 20 and $13 \mu \mathrm{L}$, respectively, of elution buffer and the concentration and quality of the extracted RNA were determined using a NanoDrop ND-1000 spectrophotometer (Thermo Scientific, Waltham, MA, USA) and 2100 Bioanalyzer (Agilent Technologies Inc., Santa Clara, CA, USA). The RNA (100 ng) was reverse transcribed into cDNA using the High-Capacity cDNA Reverse Transcription kit (Applied Biosystems) according to manufacturer's protocol and stored at $-20^{\circ} \mathrm{C}$ until use.

\subsection{Real-time PCR ( $q P C R$ ) by fluidigm biomark ${ }^{\mathrm{TM}} \mathrm{HD}$ system}

Gene expression analysis in COCs and embryos was performed using Applied Biosystems ${ }^{\mathrm{TM}}$ TaqMan ${ }^{\circ}$ Assays, specific for Bos taurus species. The mRNA abundance of 96 genes was analyzed, as indicated in Table SM.1 for COCs and Table SM.2 for embryos according to functional categories (Supplementary data). Prior to qPCR thermal cycling, each sample was submitted to sequence-specific preamplification process as follows: $1.25 \mu \mathrm{L}$ assay mix (Taqman assay was pooled to a final concentration of $0.2 \times$ for each of the 96 assays), $2.5 \mu \mathrm{L}$ TaqMan PreAmp
Master Mix (Applied Biosystems, \#4391128) and $1.25 \mu \mathrm{L}$ cDNA (5 ng/ uL). The reactions were activated at $95^{\circ} \mathrm{C}$ for $10 \mathrm{~min}$ followed by denaturing at $95{ }^{\circ} \mathrm{C}$ for $15 \mathrm{~s}$, and annealing and amplification at $60^{\circ} \mathrm{C}$ for $4 \mathrm{~min}$ for 14 cycles. Preamplified products were diluted 6 -fold prior to RT-qPCR analysis. For gene expression analysis, the sample solution prepared consisted of $2.25 \mu \mathrm{L}$ cDNA (preamplified products), $2.5 \mu \mathrm{L}$ TaqMan Universal PCR Master Mix $(2 \times$, Applied Biosystems) and $0.25 \mu \mathrm{L} 20 \times$ GE Sample Loading Reagent (Fluidigm); and the assay solution: $2.5 \mu \mathrm{L} 20 \times$ TaqMan Gene Expression Assay (Applied Biosystems) and $2.5 \mu \mathrm{L} 2 \times$ Assay Loading Reagent (Fluidigm). The 96.96 Dynamic Array ${ }^{\mathrm{TM}}$ Integrated Fluidic Circuits (Fluidigm) chip was used to data collection. After priming, the chip was loaded with $5 \mu \mathrm{L}$ of each assay solution and $5 \mu \mathrm{L}$ of each sample solution. The qPCR thermal cycling was performed in the Biomark HD System (Fluidigm, South San Francisco, CA, USA) using the protocol TaqMan GE $96 \times 96$ Standard, that consisted of $5 \mathrm{~min}$ of initial enzyme activation at $95^{\circ} \mathrm{C}$, followed by 40 cycles of denaturation and extension $\left(95^{\circ} \mathrm{C}\right.$ for $15 \mathrm{~s}$ followed by $60{ }^{\circ} \mathrm{C}$ for $60 \mathrm{~s}$ ). The relative expression of target gene in each sample was calculated using the 2- $\Delta \mathrm{Ct}$ method [33] using the mean of control group as calibrator. Data was normalized using the geometric mean of the most stable reference genes calculated using DataAssist software analysis (COCs: ACTB, PPIA and SDHA; embryos: HMBS, HPRT1 and SF3A1 and embryos cultured with sildenafil: GAPDH, HPRT1 and PPIA).

\subsection{Statistical analysis}

Statistical analyses were performed using the JMP software Version 7.0 (SAS Institute Inc., Cary, NC, USA. Data were tested for normal distribution and homogeneity of variance and were transformed to arcsine (embryonic development), log10 (lipid content) and log (gene expression) when these criteria were not met. The effects of the treatments on lipid content, gene expression and embryonic development were analyzed by one-way ANOVA followed by Tukey parametric post hoc testing or non-parametric Kruskal-Wallis test. Differences with probabilities of $\mathrm{P}<0.05$ were considered significant.

\section{Results}

\subsection{Influence of NPPC and/or sildenafil during IVM on lipid content in oocytes}

The presence of NPPC in the maturation medium reduced lipid content in oocytes after $24 \mathrm{~h}$ in culture compared with the control group (16.10 and 20.60 FI, respectively, $\mathrm{P}<0.05)$ but the effect was lost when combined with sildenafil (20.46 FI, P > 0.05) (Fig. 1). Furthermore, the presence of sildenafil alone did not affect the lipid content in oocytes (20.78 FI, P > 0.05).

\subsection{Influence of NPPC and/or sildenafil during IVM on gene expression in COCs}

The effect of NPPC and/or sildenafil during IVM on transcript accumulation in COCs was assessed and the only effect observed was that the relative abundance for PTX3 increased after NPPC treatment compared with the other groups $(\mathrm{P}<0.05$; Fig. $2 \mathrm{E})$.

\subsection{Influence of NPPC and/or sildenafil during IVM on embryo production}

None of the treatments during IVM (NPPC, sildenafil, or both) affected cleavage $(P>0.05)$ and blastocyst rates $(P>0.05)$. However, we detected a positive effect of NPPC during IVM on hatched blastocyst rates $\left(\mathrm{P}=0.058^{*}\right)$ (Table 1$)$. 


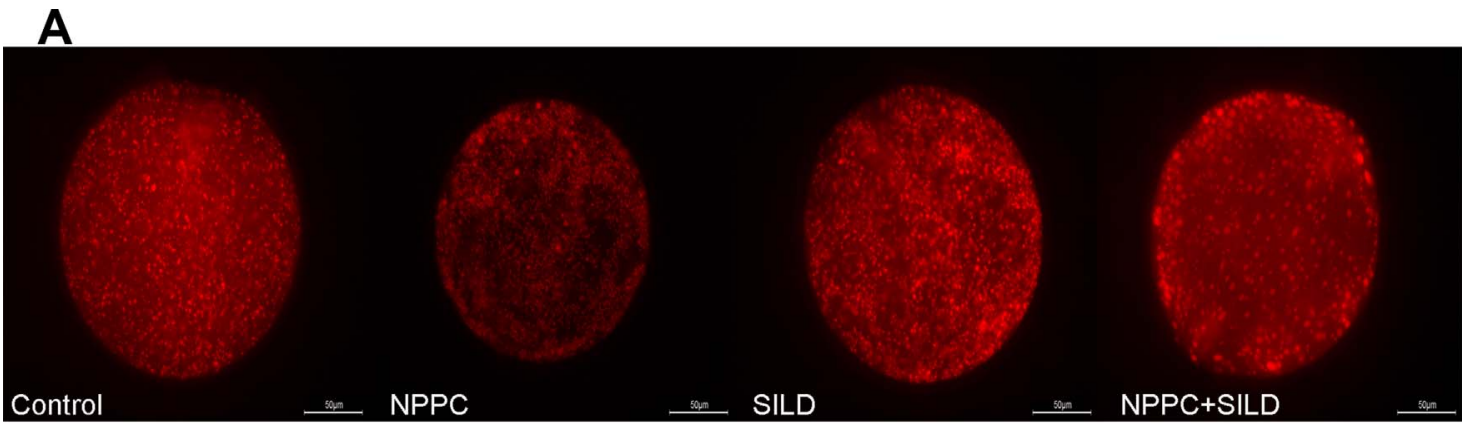

B

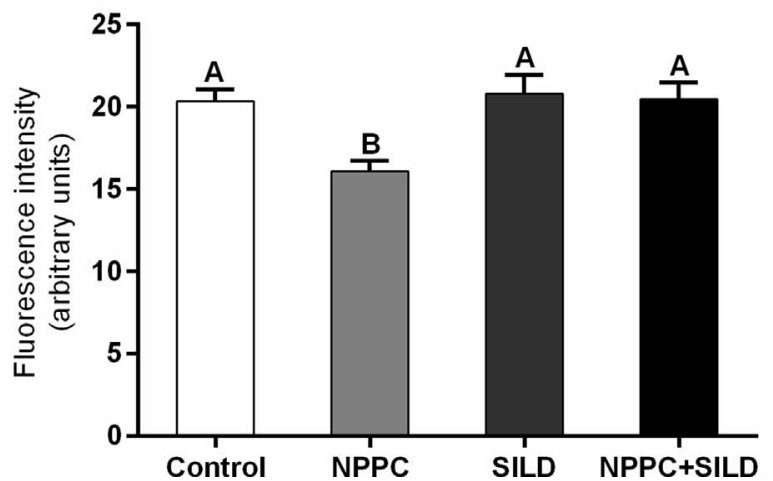

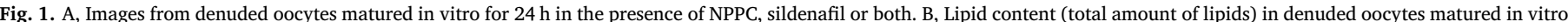
for $24 \mathrm{~h}$ in the presence of NPPC, sildenafil or both. Different letters indicate differences among treatments $(P<0.05, \mathrm{~N}=70-81$ oocytes per group).

\subsection{Influence of NPPC and/or sildenafil during IVM on lipid content in embryos}

When embryos produced from COCs, matured in the different treatments during IVM, were analyzed for cytoplasmic lipid accumulation, no effects were observed (control 47.57 FI; NPPC 50.70 FI; sildenafil $46.20 \mathrm{FI}$ and NPPC plus SILD $45.61 \mathrm{FI}$, Fig. 3, P > 0.05).

\subsection{Influence of NPPC and/or sildenafil during IVM on gene expression in} embryos

Analysis of embryo transcripts showed that when COCs were matured with NPPC, transcript abundance was not different from the control group (Fig. 4, P > 0.05). Only FOXO3 was increased relative to sildenafil or NPPC plus sildenafil (Fig. 4A, P > 0.05). Sildenafil treatment during IVM increased HSF1 and PAF1 (Fig. 4B and D, P < 0.05) and decreased REST transcript abundance relative to controls (Fig. 4E, $P<0.05$ ). When both NPPC and sildenafil were used during IVM, only REST was lower than the control (Fig. 4E, P $<0.05$ ). PAF1 and HSPA1A were reduced relative to sildenafil alone and FOXO3 relative to NPPC alone (Fig. 4, P < 0.05).

3.6. Influence of NPPC and/or sildenafil during IVM and sildenafil during IVC on embryo production

The effects of NPPC and/or sildenafil during IVM and of supplementation with sildenafil during IVC on the rates of cleavage and blastocyst are presented in Table 2. Sildenafil treatment during IVC did
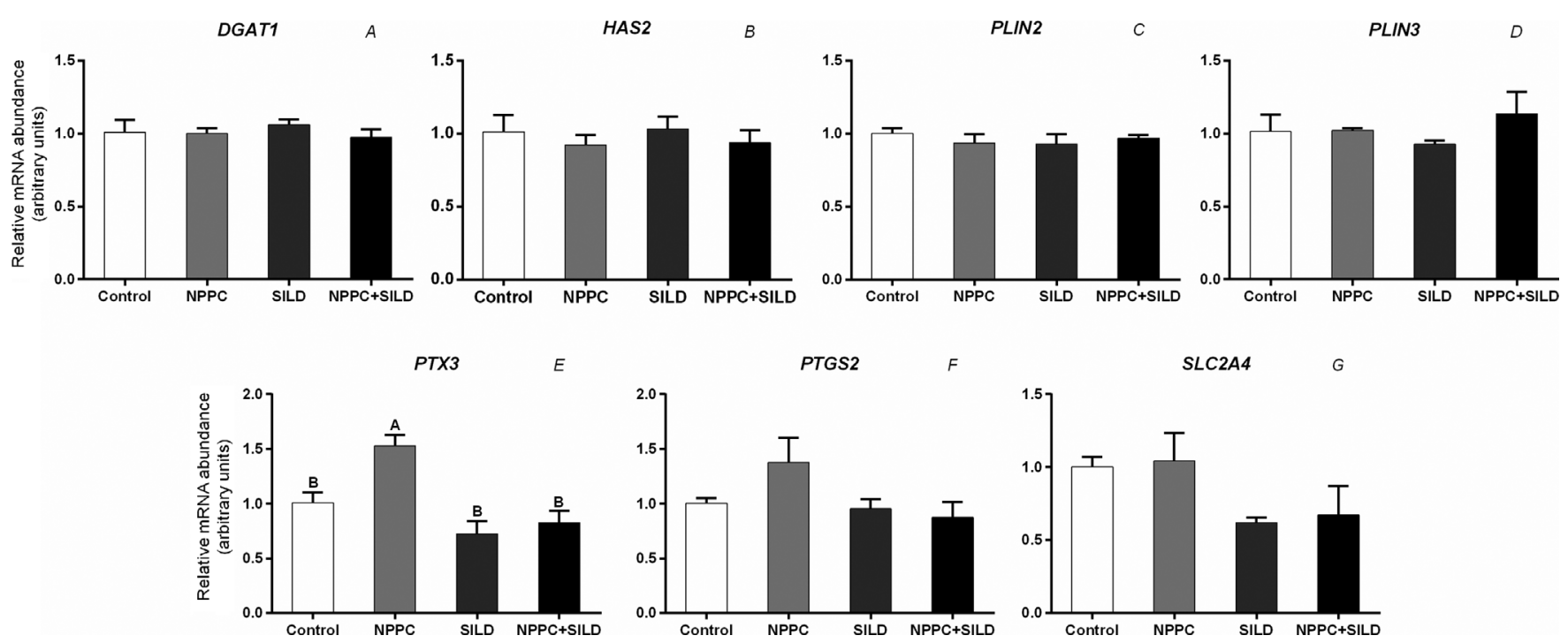

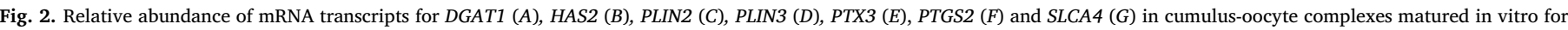
$24 \mathrm{~h}$ in the presence of NPPC, sildenafil or both. Different letters for each figure differences among treatments $(P<0.05)$. 
not affect embryo development compared to the control group (without treatment in IVM and IVC, P > 0.05). NPPC and/or sildenafil during IVM and sildenafil supplementation during IVC also did not affect cleavage rates and embryo development $(\mathrm{P}>0.05)$.

\subsection{Influence on lipid content in embryos of NPPC and/or sildenafil during IVM and sildenafil during IVC}

The effects of NPPC and/or sildenafil during IVM and of supplementation with sildenafil during IVC were also evaluated for lipid accumulation in the resulting embryos. The results are presented in Fig. 5. When sildenafil was added only during IVC, lipid contents were unchanged relative to the control without any treatments $(P<0.05)$. However, embryos cultured with sildenafil during IVC from COCs matured with NPPC or sildenafil showed higher lipid content (54.90 and 56.89 FI, respectively, $\mathrm{P}<0.05$ ) compared to the group without any treatment (47.57 FI, $\mathrm{P}<0.05$ ). When the embryos were cultured in the presence of sildenafil from COCs matured with the combined NPPC plus sildenafil treatment, no differences were observed when compared to the control group without any treatment (49.16 FI and 53.49 FI, respectively, $\mathrm{P}>0.05)$.

\subsection{Influence of NPPC and/or sildenafil during IVM and sildenafil during IVC on gene expression in embryos}

The addition of sildenafil only during IVC reduced the expression of ATF4 and COX2 compared to untreated controls ( $\mathrm{P} \leq 0.05$ ) (Fig. 6). When NPPC was used during IVM and sildenafil during IVC, ATF4 was also reduced relative to the untreated control $(\mathrm{P} \leq 0.05)$, but it was similar to the group treated only with sildenafil during IVC $(P>0.05)$. When sildenafil was used during IVM and IVC, SOX2 increased relative to the control with sildenafil during IVC only $(P \leq 0.05)$. The combination of NPPC and sildenafil during IVM, followed by IVC with sildenafil, affected both DNMT3 transcripts. DNMT3 B increased relative to the untreated control and NPPC alone $(\mathrm{P} \leq 0.05)$ while DNMT3A was also increased relative to sildenafil, either in IVM or in IVC ( $\mathrm{P} \leq 0.05$ ). XBP1 transcripts were increased only relative to the control with sildenafil during IVC $(\mathrm{P} \leq 0.05)$.

\section{Discussion}

The excessive accumulation of intracellular lipid droplets during in vitro embryonic development damages the quality of embryos, possibly by increasing their sensitivity to oxidative stress and cryopreservation $[34,35]$. The precise mechanisms involved in lipid accumulation remain unclear but some evidence suggests that undefined components in the culture medium are potential sources for lipid accumulation [36]. Several approaches focus on the reduction of lipid accumulation in IVPembryos by modifications in the culture media, aiming for improvements in embryonic performance and quality.

To our knowledge, the present study is the first to evaluate the influence of NPPC, along with the PDE5 inhibitor sildenafil, during IVM on the lipid content of oocytes and embryos. We also evaluated the relative abundance of transcripts related to oocyte competence, pathways involved in maturation process in COCs, and transcripts related to embryo quality in blastocysts after embryo culture without or with sildenafil. Our findings support the hypothesis that the NPPC/NPR2/ cGMP pathway may influence the lipid metabolism of bovine COCs and have an impact on embryos as well.

In the present study, the effect of NPPC during IVM decreased cytoplasmic lipid accumulation in oocytes. The effects of cGMP manipulation on lipid metabolism have also been reported in adipocytes [37] and were shown in bovine oocytes and embryos for the first time by Schwarz and collaborators [20]. The influence of cGMP, stimulated by NPPC, seems to exert a similar effect as described for cAMP, whose higher levels stimulate lipolysis and reduce the amount of lipids in 

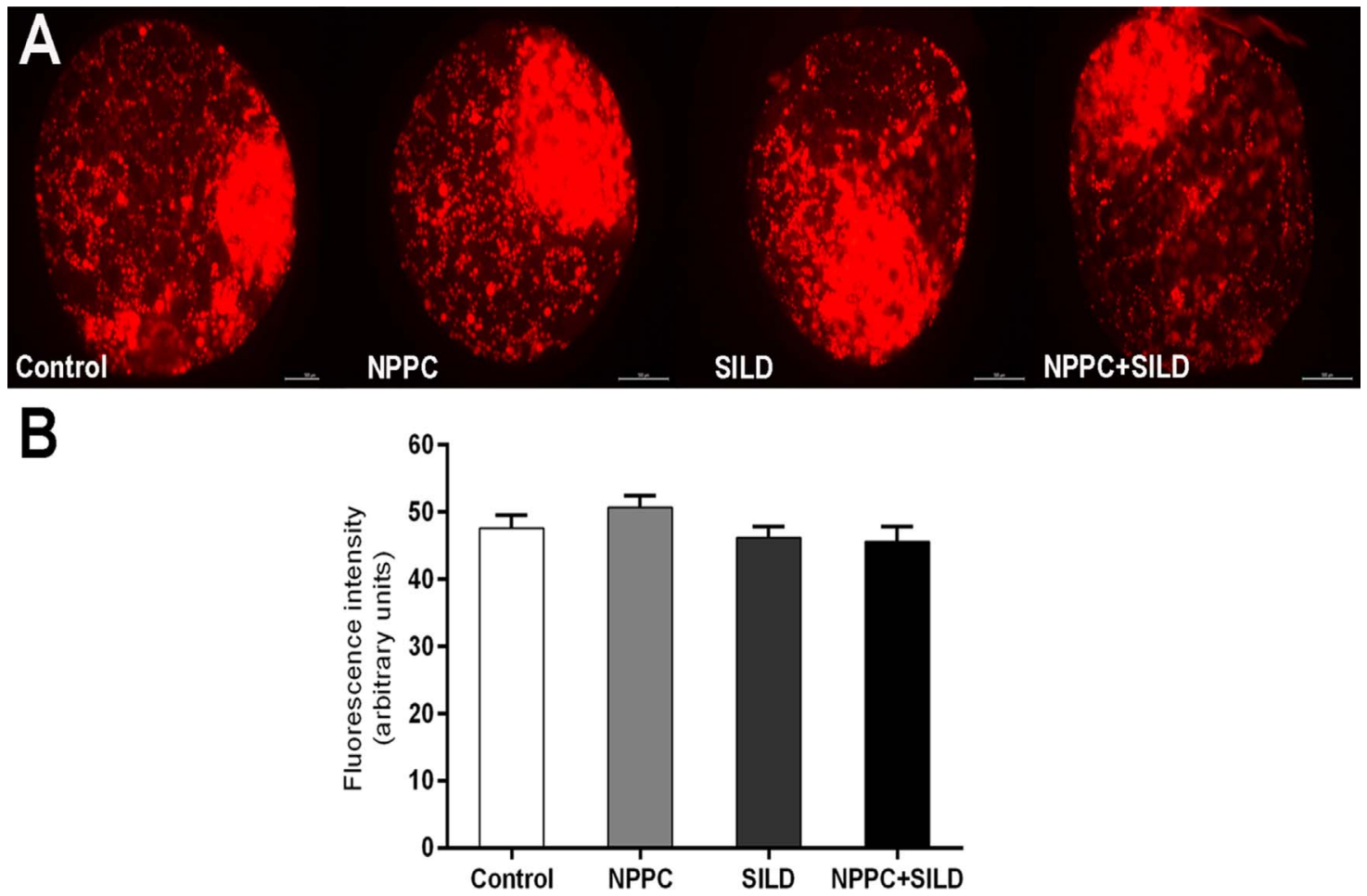

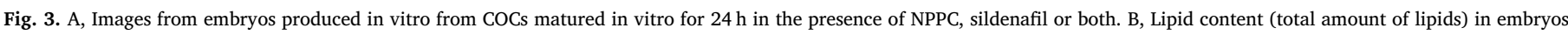
produced in vitro from COCs matured in vitro for $24 \mathrm{~h}$ in the presence of NPPC, sildenafil or both. ( $\mathrm{N}=40-45$ embryos per group).

porcine [32] and bovine oocytes [38]. However, since the association of NPPC with sildenafil during IVM did not affect the lipid content of oocytes, we consider that the fine adjustment of cGMP levels, caused by NPPC (active cGMP production) and sildenafil (inhibitor of cGMP degradation) via the PKG phosphorylation pathway, was responsible for this result. Based on our results, we speculate that the lipolytic effects of NPPC on reducing LC in bovine matured oocytes may also improve the cryotolerance of the oocytes in a manner similar to that previously reported for porcine matured oocytes utilizing forskolin during IVM
(cAMP modulators)[32].

Franciosi et al. [12] reported that NPPC supplementation during bovine IVM affected intercellular communication between oocytes and cumulus cells, prolonging the opening time of gap junctions and promoting the transport of metabolites, nutrients, and regulatory molecules in exchanges that benefit the oocyte. Additionally, we investigated the effect of NPPC on genes related to cumulus cell expansion, which may influence oocyte competence, analyzing PTX3, HAS2, and PTGS2. Only the expression of PTX3 was significantly
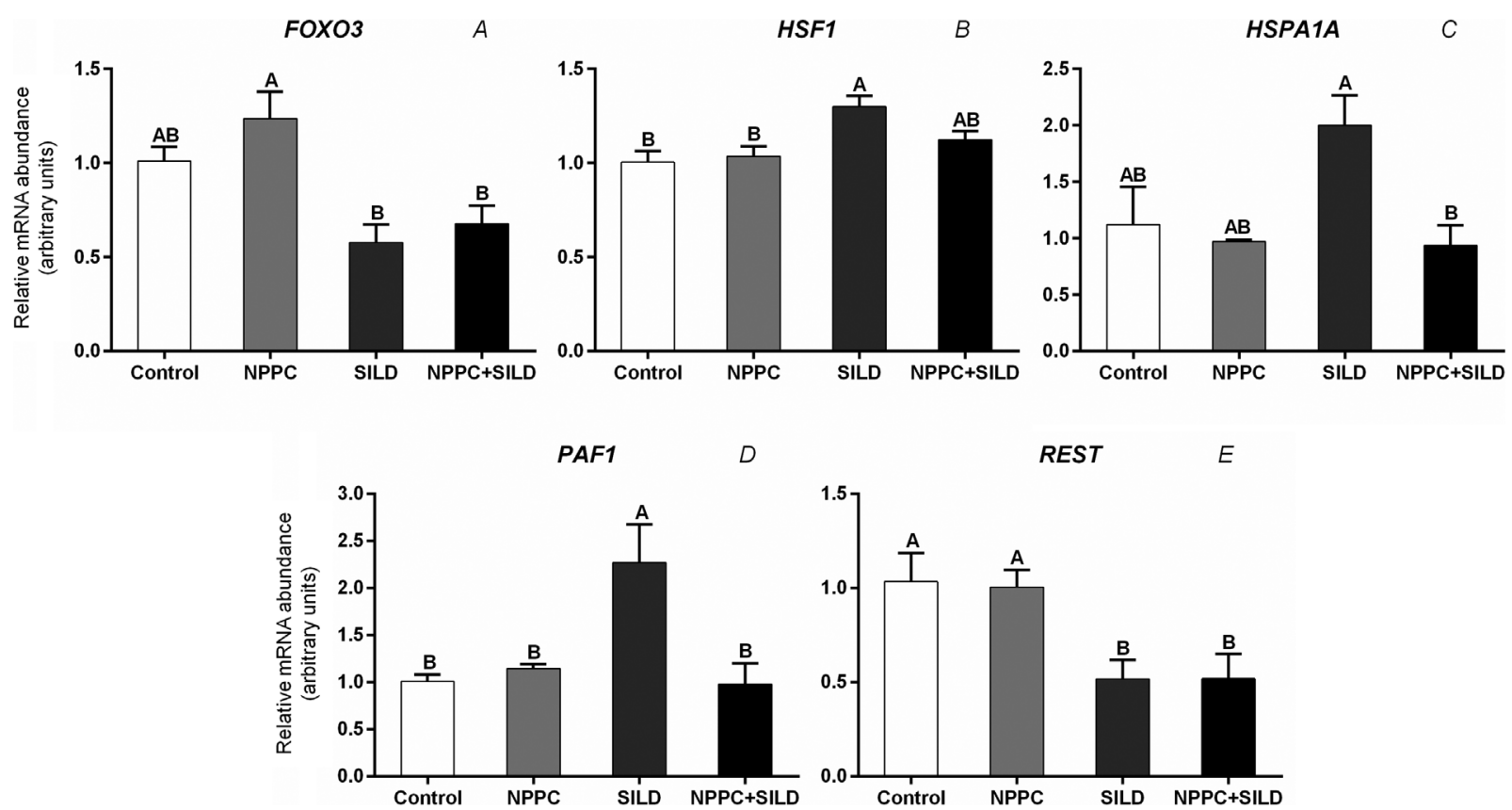

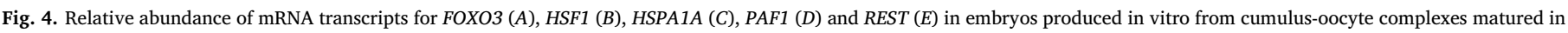
vitro for $24 \mathrm{~h}$ in the presence of NPPC, sildenafil or both. Different letters for each figure differences among treatments $(P<0.05)$. 
upregulated after NPPC treatment. PTX3 is involved in cumulus cell physiology, extracellular matrix formation, and cumulus expansion. It is also used as a non-invasive marker of oocyte quality and competence for embryonic development [39-41]. Thus, we assessed embryonic development rates in this study and observed only a slight effect on the rates of hatched blastocysts $\left(\mathrm{P}=0.058^{*}\right)$ from COCs matured in presence of NPPC. This effect on hatched blastocysts corroborates the results reported by Franciosi et al. [12]. Additionally, we suggested that NPPC supplementation during IVM would improve embryo development and quality in cattle.

The reduced lipid content of oocytes treated with NPPC during IVM did not persist in blastocysts since there was no difference in the cytoplasmic lipid content of embryos among the groups. We consider that a possible compensatory mechanism was responsible for blastocysts recovering their lipid content. Though unclear, a similar compensatory mechanism was also reported previously by Schwarz et al. [20]. In that work, the combination of FCS and sildenafil during IVM reduced lipid content in oocytes but generated embryos with higher lipid content than those produced from oocytes matured with BSA only. However, the signaling pathways involved in this lipid accumulation process are still unknown.

Several gene pathways were also investigated in embryos produced from COCs treated with the cGMP modulators, NPPC and sildenafil, in order to understand their possible role in cytoplasmic lipid accumulation (Table SM.2). Embryos from COCs matured with NPPC increased the FOXO3 relative transcript abundance. This gene may be participating in the lipid compensatory mechanism. FOXOs regulate the expression of genes involved in mechanisms such as apoptosis, oxidative stress resistance, DNA repair, glucose metabolism, and energy homeostasis [42]. Xioung et al. [43] showed that a liver-specific triple knockout of FOXO1, FOXO3, and FOXO4 resulted in increased hepatic serum triglyceride levels. Consequently, we believe the increase in FOXO3 transcript abundance was a result of excessive accumulation of lipids during culture with FCS.

The embryos analyzed from COCs matured with sildenafil increased the relative abundance of heat stress-related genes HSF1 and HSPA1A. $\mathrm{HSF}$, as a transcription factor, might be involved in the control of heat shock gene expression during early mammalian embryogenesis [44]. Probably, because of the increased abundance of HSF1, the relative abundance of the $70 \mathrm{kDa}$ heat shock protein $1 \mathrm{~A}$ (HSPA1A) also increased. HSPA1A has important roles as a molecular chaperone and in preventing apoptosis under various stress conditions, such as heat stress [45]. Likely, the presence of sildenafil during IVM triggered some mechanism in response to stress. Additionally, two other genes, $P A F$ and $R E S T$, were affected by the same treatment during IVM (sildenafil). Ding et al. [46] demonstrated that PAF1C plays an important role in maintaining embryonic stem cell (ESC) identity; the action is performed on OCT4 expression levels, a key factor for maintaining ESC. Other factors associated with ESCs are RE1-silencing transcription factor (REST) and the action of REST on maintenance of pluripotency and differentiation. In the present study, PAF1 was upregulated and REST was downregulated in embryos from COCs matured in the sildenafil treatment. We consider that the inhibition of PDE5 by sildenafil during IVM caused no effect on embryo quality but could affect the kinetics of cell differentiation during early embryo development, in turn affecting hatched blastocyst rates.

We evaluated the effects of sildenafil during IVC on embryos. The presence of sildenafil during IVC until D7 did not affect embryo production. Nonetheless, the presence of PDE5 inhibitor during IVC increased lipid content in embryos. Our results are the first to suggest that cGMP modulators during IVC might affect embryo lipid metabolism. We expected a decrease in the lipid content via the cGMP/PKG/HSL pathway, such as reviewed by Lafontan et al. [18]; however, the embryos cultured with sildenafil increased cytoplasmic lipid accumulation.

The mechanisms that lead to this lipid accumulation remain obscure 


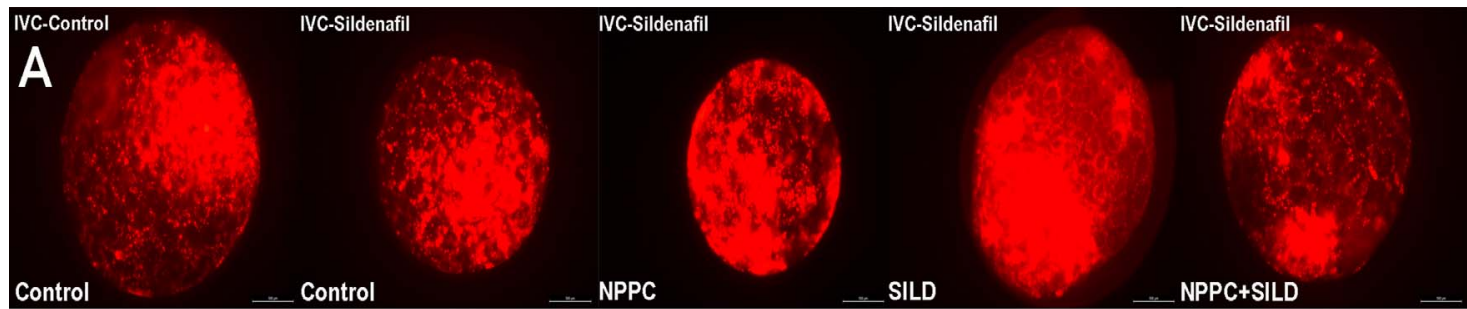
B

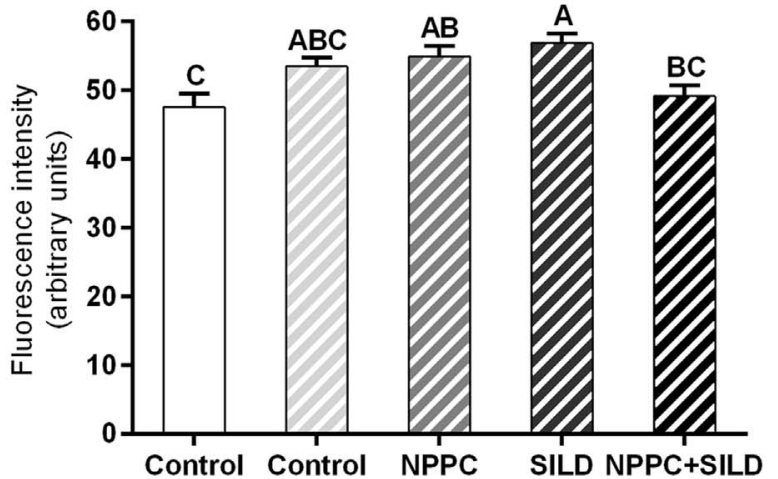

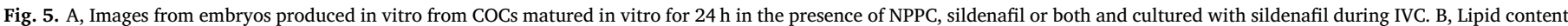

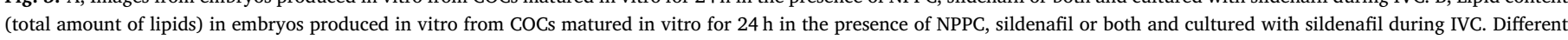
letters indicate differences among treatments $(P<0.05, \mathrm{~N}=36-49$ embryos per group).

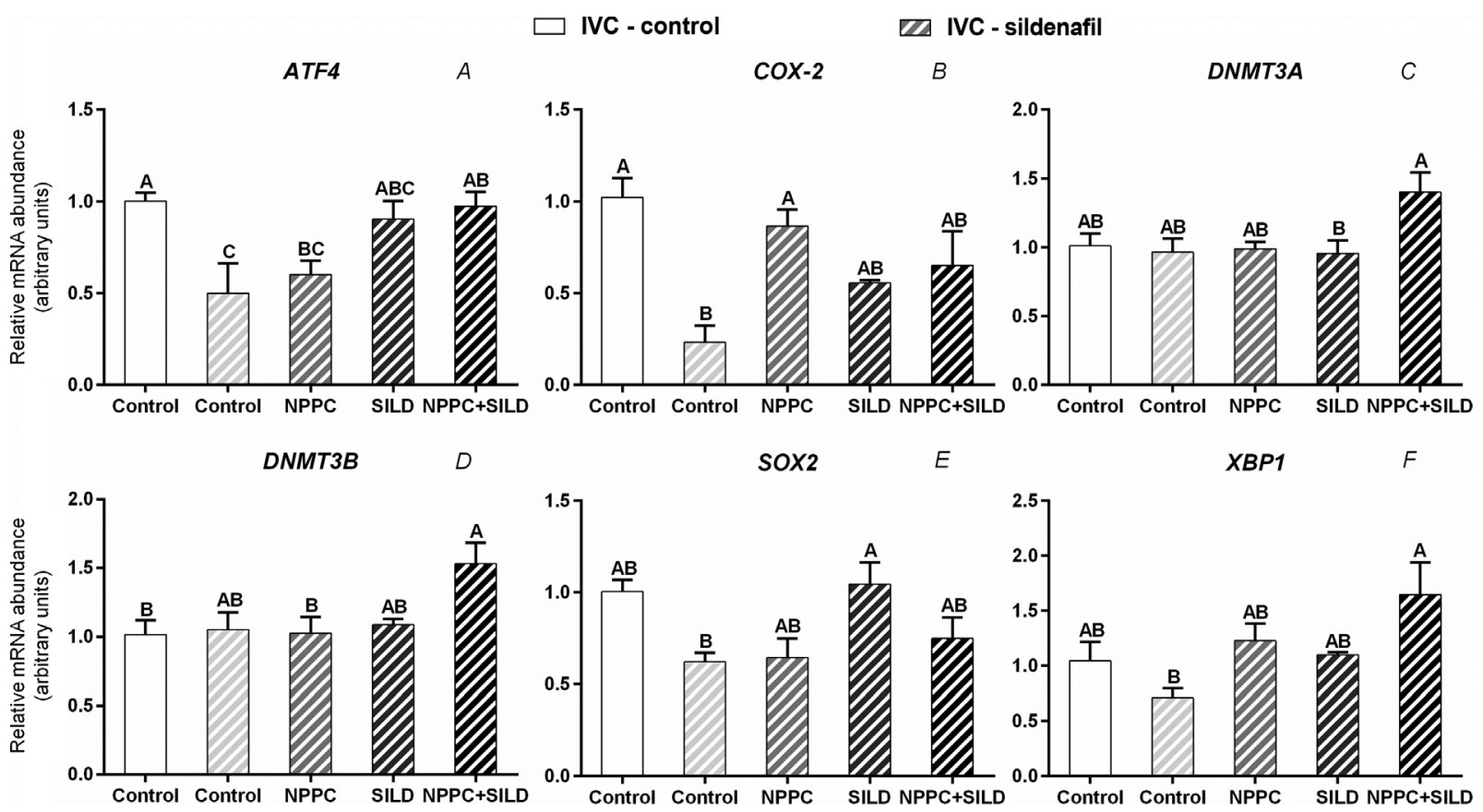

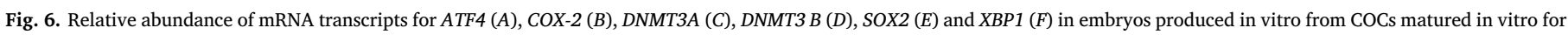
$24 \mathrm{~h}$ in the presence of NPPC, sildenafil or both and cultured with sildenafil during IVC. Different letters for each figure differences among treatments $(P<0.05)$.

but evidence suggests that undefined components in the culture medium, such as FCS, may result in abnormalities in embryonic energy metabolism. Still, we consider that the increase in cytoplasmic lipid content in embryos could be a result of a compensatory mechanism in lipid metabolism in the cGMP/PKG pathway caused by the PDE5 inhibitor during IVC, affecting lipid metabolism and enhancing lipid accumulation in embryonic cells.

Many genes involved in lipid metabolism were analyzed in embryos (Table SM.2); however, these genes were not affected, suggesting that different pathways with other candidate genes, not investigated in this work, might be involved in the cytoplasmic lipid accumulation of blastocysts. Another possibility is that these pathways participate in increasing lipid content at other embryo developmental stages. Sudano et al. [47] demonstrated stage-specific relative abundance of mRNA transcripts for ACSL3, ELOVL5, and ELOVL6 and lipid content during early bovine embryo development. These authors observed an increase in lipid accumulation and relative abundance of mRNA for ACSL3, ELOVL5, and ELOVL6 in embryos at the morulae stage. Based on this fact, it is possible that the effects of sildenafil during IVC could have affected the expression of those lipid metabolism genes during early stages of embryonic development (8-16 cells at initial blastocyst) and still affected cytoplasmic lipid accumulation. 
In relation to genes associated with embryo quality, two endoplasmic reticulum stress markers (ATF4 and XBP1) showed a decrease in relative abundance in embryos from COCs matured in the control group and cultured with sildenafil during IVC. The exposure to an excessive concentration of saturated fat is associated with mitochondrial damage, which is in turn related to the induction of oxidative stress and endoplasmic reticulum stress [48]. However, in our study, the increase in cytoplasmic lipid content produced by sildenafil during IVC does not seem to induce stress in the endoplasmic reticulum, since the relative mRNA abundance of ATF4 and XBP1 was decreased in embryos produced from COCs matured relative to the sildenafil treatment or the control group.

The embryos cultured with sildenafil from COCs matured in the NPPC plus sildenafil treatment showed increased relative mRNA abundance for DNMT3A and DNMT3B. The establishment and maintenance of a hypermethylated genome are crucial for embryonic development beyond gastrulation [49]. Finally, the relative mRNA abundance of COX2 and SOX2 was decreased in embryos from COCs matured in the control group and cultured with sildenafil. SOX2 is a pluripotency marker and the action of SOX2 is mediated by its regulatory effect on the pluripotency network, demonstrated in in vivo [50] and in vitro [51] models. COX2 has been associated with successful pregnancy establishment and calf delivery, probably due to its essential function in differentiation, proliferation, and anti-apoptosis pathways [52]. In the current study, both genes (SOX2 and COX2) were downregulated in embryos from COCs matured in the control group and cultured with sildenafil. However, we consider that change in only two genes does not represent a significant decrease in embryo quality since we analyzed 96 genes directly or indirectly related to embryonic quality.

We demonstrated, in the current study, that the use of NPPC during IVM and sildenafil during IVC affected lipid metabolism in oocytes and embryos, corroborating the results of Schwarz et al. [20] and describing the effects of cGMP/PKG modulation on lipid metabolism in bovine oocytes and embryos. Still, the effects of NPPC during IVM on cytoplasmic lipid accumulation in bovine oocytes and the effects on genes involved in cumulus cell expansion, favor its use during IVM of bovine oocytes. Additionally, IVC supplemented with sildenafil also affected lipid metabolism, increasing cytoplasmic lipid accumulation. The explanations for these findings are unclear but one possibility could be activation of a compensatory mechanism during IVC that recovers lipid concentrations. Furthermore, in vitro culture with sildenafil increased cytoplasmic lipid accumulation in embryos but did not compromise embryo quality.

\section{Declaration of conflicting interests}

The author(s) declared no potential conflicts of interest with respect to the research, authorship, and/or publication of this article.

\section{Acknowledgments}

We acknowledge São Paulo Research Foundation (FAPESP) for funding (Grant 2012/50533-2, 2013/05083-1 and 2015/20379-0) and fellowships of RCB (2014/25072-7), EMR (12/23409-9), EMP (13/ 07730-4) and KRLS (12/00170-0).

\section{Appendix A. Supplementary data}

Supplementary data associated with this article can be found, in the online version, at https://doi.org/10.1016/j.repbio.2018.01.004.

\section{References}

[1] Smitz JEJ, Thompson JG, Gilchrist RB. The promise of in vitro maturation in assisted reproduction and fertility preservation. Semin Reprod Med 2011;29:24-37. http://dx.doi.org/10.1055/s-0030-1268701.

[2] Gilchrist RB. Recent insights into oocyte-follicle cell interactions provide opportunities for the development of new approaches to in vitro maturation. Reprod Fertil Dev 2011;23:23-31. http://dx.doi.org/10.1071/RD10225.

[3] Mattioli M, Galeati G, Barboni B, Seren E. Concentration of cylic AMP during the maturation of pig oocytes in vivo and in vitro. J Reprod Fertil 1994;100:403-9.

[4] Luciano AM, Modina S, Vassena R, Milanesi E, Lauria A, Gandolfi F. Role of intracellular cyclic adenosine $3^{\prime}, 5^{\prime}$-monophosphate concentration and oocyte-cumulus cells communications on the acquisition of the developmental competence during in vitro maturation of bovine oocyte. Biol Reprod 2004;70:465-72.

[5] Sirard MA, First NL. In vitro inhibition of oocyte nuclear maturation in the bovine. Biol Reprod 1988;39:229-34.

[6] Chen J, Chi MM, Moley KH, Downs SM. cAMP pulsing of denuded mouse oocytes increases meiotic resumption via activation of AMP-activated protein kinase. Reproduction 2009;138:759-70. http://dx.doi.org/10.1530/REP-08-0535.

[7] Albuz FK, Sasseville M, Lane M, Armstrong DT, Thompson JG, Gilchrist RB. Simulated physiological oocyte maturation (SPOM): a novel in vitro maturation system that substantially improves embryo yield and pregnancy outcomes. Hum Reprod 2010;25:2999-3011.

[8] Bu S, Xie H, Tao Y, Wang J, Xia G. Nitric oxide influences the maturation of cumulus cell-enclosed mouse oocytes cultured in spontaneous maturation medium and hypoxanthine-supplemented medium through different signaling pathways. Mol Cell Endocrinol 2004;223:85-93.

[9] Schwarz KRL, Pires PRL, Mesquita LG, Chiaratti MR, Leal CLV. Effect of nitric oxide on the cyclic guanosine monophosphate (cGMP) pathway during meiosis resumption in bovine oocytes. Theriogenology 2014;81:556-64.

[10] Zhang M, Su Y-Q, Sugiura K, Xia G, Eppig JJ. Granulosa cell ligand NPPC an its receptor NPR2 maintain meiotic arrest in mouse oocytes. Science 2010;330(80):366-9.

[11] Santiquet N, Papillon-Dion E, Djender N, Guillemette C, Richard FJ. New elements in the C-type natriuretic peptide signaling pathway inhibiting swine in vitro oocyte meiotic resumption. Biol Reprod 2014;91:16. http://dx.doi.org/10.1095/ biolreprod.113.114132.

[12] Franciosi F, Coticchio G, Lodde V, Tessaro I, Modina SC, Fadini R, et al. Natriuretic peptide precursor $\mathrm{C}$ delays meiotic resumption and sustains gap junction-mediated communication in bovine cumulus-enclosed oocytes. Biol Reprod 2014;91:61.

[13] Zhang J, Wei Q, Cai J, Zhao X, Ma B. Effect of C-type natriuretic peptide on maturation and developmental competence of goat oocytes matured in vitro. PLoS One 2015;10:1-10. http://dx.doi.org/10.1371/journal.pone.0132318.

[14] Potter LR. Guanylyl cyclase structure, function and regulation. Cell Signal 2011;23:1921-6.

[15] Francis SH, Blount MA, Corbin JD. Mammalian cyclic nucleotide phosphodiesterases: molecular mechanisms and physiological functions. Physiol Rev 2011;91:651-90.

[16] Sasseville M, Côté N, Gagnon M-C, Richard FJ. Up-regulation of 3`5'-cyclic guanosine monophosphate-specific phosphodiesterase in the porcine cumulus-oocyte complex affects steroidogenesis during in vitro maturation. Endocrinology 2008;149:5568-76.

[17] Sengenès C, Bouloumié A, Hauner H, Berlan M, Busse R, Lafontan M, et al. Involvement of a cGMP-dependent pathway in the natriuretic peptide-mediated hormone-sensitive lipase phosphorylation in human adipocytes. J Biol Chem 2003;278:48617-26. http://dx.doi.org/10.1074/jbc.M303713200.

[18] Lafontan M, Moro C, Berlan M, Crampes F, Sengenes C, Galitzky J. Control of lipolysis by natriuretic peptides and cyclic GMP. Trends Endocrinol Metab 2008;19:130-7. http://dx.doi.org/10.1016/j.tem.2007.11.006.

[19] Ferguson EM, Leese HJ. Triglyceride content of bovine oocytes and early embryos. J Reprod Fertil 1999;116:373-8. http://dx.doi.org/10.1530/jrf.0.1160373.

[20] Schwarz KRLK, Botigelli RRC, Del Collado M, Cavallari de Castro F, Fernandes H, Paschoal DMD, et al. Effects of fetal calf serum on cGMP pathway and oocyte lipid metabolism in vitro. Reprod Fertil Dev 2016;29. http://dx.doi.org/10.1071/ RD15512.

[21] Del Collado M, Botigelli RC, Schwarz KRL, Elias C, Leal CLV, Andrade AFC, et al. 247 effects of sildenafil or snap supplementation, or, both, during in vitro maturation on lipid and reactive oxygen species accumulation in bovine oocytes and embryos. Reprod Fertil Dev 2014. 213-213.

[22] Del Collado M, Saraiva NZ, Lopes FL, Gaspar RC, Padilha LC, Costa RR, et al. Influence of bovine serum albumin and fetal bovine serum supplementation during in vitro maturation on lipid and mitochondrial behaviour in oocytes and lipid accumulation in bovine embryos. Reprod Fertil Dev 2016;28:1721-32. http://dx.doi. org/10.1071/RD15067.

[23] Sudano MJ, Santos VG, Tata A, Ferreira CR, Paschoal DM, Machado R, et al. Phosphatidylcholine and sphingomyelin profiles vary in bos taurus indicus and bos taurus in vitro- and in vivo-produced blastocysts. Biol Reprod 2012;87:130. http:// dx.doi.org/10.1095/biolreprod.112.102897.

[24] De La Torre-Sanchez JF, Gardner DK, Preis K, Gibbons J, Seidel GE. Metabolic regulation of in-vitro-produced bovine embryos II. Effects of phenazine ethosulfate, sodium azide and 2,4-dinitrophenol during post-compaction development on glucose metabolism and lipid accumulation. Reprod Fertil Dev 2006;18:597-607. http://dx.doi.org/10.1071/RD05064.

[25] Barceló-Fimbres M, Seidel GE. Effects of fetal calf serum, phenazine ethosulfate and either glucose or fructose during in vitro culture of bovine embryos on embryonic development after cryopreservation. Mol Reprod Dev 2007;74:1395-405. http:// dx.doi.org/10.1002/mrd.20699.

[26] de Loos F, Kastrop P, Van Maurik P, Van Beneden TH, Kruip TA. Heterologous cell contacts and metabolic coupling in bovine cumulus oocyte complexes. Mol Reprod Dev 1991;28:255-9. 
[27] Parrish JJ, Krogenaes A, Susko-Parrish JL. Effect of bovine sperm separation by either swim-up or Percoll method on success of in vitro fertilization and early embryonic development. Theriogenology 1995;44:859-69. http://dx.doi.org/10. 1016/0093-691X(95)00271-9.

[28] Parrish JJ. Bovine in vitro fertilization: in vitro oocyte maturation and sperm capacitation with heparin. Theriogenology 2014;81:67-73. http://dx.doi.org/10. 1016/j.theriogenology.2013.08.005.

[29] Holm P, Booth PJ, Schmidt MH, Greve T, Callesen H. High bovine blastocyst development in a static in vitro production system using SOFaa medium supplemented with sodium citrate and myo-inositol with or without serum-proteins. Theriogenology 1999;52:683-700. http://dx.doi.org/10.1016/S0093-691X(99) 00162-4.

[30] Stringfellow DA, Seidel SM. Society. IET. Manual of the International Embryo Transfer Society: a procedural guide and general information for the use of embryo transfer technology emphasizing sanitary procedures. Savory, Ill. International Embryo Transfer Society; 2007.

[31] Romek M, Gajda B, Krzysztofowicz E, Kepczynski M, Smorag Z. New technique to quantify the lipid composition of lipid droplets in porcine oocytes and pre-implantation embryos using Nile Red fluorescent probe. Theriogenology 2011;75:42-54. http://dx.doi.org/10.1016/j.theriogenology.2010.06.040. S0093691X(10)00367-5[pii]n.

[32] Fu XW, Wu GQ, Li JJ, Hou YP, Zhou G Bin, Lun-Suo, et al. Positive effects of Forskolin (stimulator of lipolysis) treatment on cryosurvival of in vitro matured porcine oocytes. Theriogenology 2011;75:268-75. http://dx.doi.org/10.1016/j. theriogenology.2010.08.013.

[33] Livak KJ, Schmittgen TD. Analysis of relative gene expression data using real-time quantitative PCR and the 2-DDCT method. Methods 2001;25:402-8. http://dx.doi. org/10.1006/meth.2001.1262.

[34] Rizos D, Fair T, Papadopoulos S, Boland MP, Lonergan P. Developmental, qualitative, and ultrastructural differences between ovine and bovine embryos produced in vivo or in vitro. Mol Reprod Dev 2002;62:320-7. http://dx.doi.org/10.1002/mrd. 10138.

[35] Pereira RM, Carvalhais I, Pimenta J, Baptista MC, Vasques MI, Horta AEM, et al. Biopsied and vitrified bovine embryos viability is improved by trans10, cis12 conjugated linoleic acid supplementation during in vitro embryo culture. Anim Reprod Sci 2008;106:322-32. http://dx.doi.org/10.1016/j.anireprosci.2007.05. 008.

[36] Dinnyes A, Nedambale TL. Cryopreservation of manipulated embryos: tackling the double jeopardy. Reprod Fertil Dev 2009;21:45-59. http://dx.doi.org/10.1071/ RD08220.

[37] Lafontan M, Langin D. Lipolysis and lipid mobilization in human adipose tissue. Prog Lipid Res 2009;48:275-97. http://dx.doi.org/10.1016/j.plipres.2009.05.001.

[38] Razza EM, Sudano MJ, Fontes PK, Franchi FF, Santos PH, Vilela JA, et al. Bovine oocyte prematuration with cyclic adenosine monophosphate modulators: in vitro performance and semi-quantitative lipid evaluation. Anim Reprod 2017;14. 242-242.

[39] Assidi M, Dufort I, Ali A, Hamel M, Algriany O, Dielemann S, et al. Identification of potential markers of oocyte competence expressed in bovine cumulus cells matured with follicle-stimulating hormone and/or phorbol myristate acetate in vitro. Biol Reprod 2008;79:209-22. http://dx.doi.org/10.1095/biolreprod.108.067686.

[40] Uyar A, Torrealday S, Seli E. Cumulus and granulosa cell markers of oocyte and embryo quality. Fertil Steril 2013;99:997-1003. http://dx.doi.org/10.1016/j. biotechadv.2011.08.021. Secreted.

[41] Hammond ER, Stewart B, Peek JC, Shelling AN, Cree LM. Assessing embryo quality by combining non-invasive markers: early time-lapse parameters reflect gene expression in associated cumulus cells. Hum Reprod 2015;30:1850-60. http://dx.doi. org/10.1093/humrep/dev121.

[42] Webb AE, Brunet A. FOXO transcription factors: key regulators of cellular quality control. Trends Biochem Sci 2014;39:159-69. http://dx.doi.org/10.1016/j.tibs. 2014.02.003.

[43] Xiong X, Tao R, DePinho RA, Dong XC. The autophagy-related gene 14 (Atg14) is regulated by forkhead box $\mathrm{O}$ transcription factors and circadian rhythms and plays a critical role in hepatic autophagy and lipid metabolism. J Biol Chem 2012;287:39107-14. http://dx.doi.org/10.1074/jbc.M112.412569.

[44] Sakatani M, Alvarez NV, Takahashi M, Hansen PJ. Consequences of physiological heat shock beginning at the zygote stage on embryonic development and expression of stress response genes in cattle. J Dairy Sci 2012;95:3080-91. http://dx.doi.org/ 10.3168/jds.2011-4986.

[45] Costa PJ, Arndt KM. Synthetic lethal interactions suggest a role for the Saccharomyces cerevisiae Rtf1 protein in transcription elongation. Genetics 2000;156:535-47.

[46] Ding L, Paszkowski-Rogacz M, Nitzsche A, Slabicki MM, Heninger AK, Vries de I, et al. A genome-scale RNAi screen for Oct4 modulators defines a role of the Paf1 complex for embryonic stem cell identity. Cell Stem Cell 2009;4:403-15. http://dx. doi.org/10.1016/j.stem.2009.03.009.

[47] Sudano MJ, Rascado TDS, Tata A, Belaz KRA, Santos VG, Valente RS, et al. Lipidome signatures in early bovine embryo development. Theriogenology 2016;86:472-84. http://dx.doi.org/10.1016/j.theriogenology.2016.03.025.

[48] Wu LL, Russell DL, Norman RJ, Robker RL. Endoplasmic reticulum (ER) stress in cumulus-oocyte complexes impairs pentraxin-3 secretion, mitochondrial membrane potential (DeltaPsi m), and embryo development. Mol Endocrinol 2012;26:562-73. http://dx.doi.org/10.1210/me.2011-1362.

[49] Auclair G, Guibert S, Bender A, Weber M. Ontogeny of CpG island methylation and specificity of DNMT3 methyltransferases during embryonic development in the mouse. Genome Biol 2014;15:545. http://dx.doi.org/10.1186/s13059-014-0545-5.

[50] Avilion AA, Nicolis SK, Pevny LH, Perez L, Vivian N, Lovell-Badge R. Multipotent cell lineages in early mouse development depend on SOX2 function. Genes Dev 2003;17:126-40. http://dx.doi.org/10.1101/gad.224503.

[51] Takahashi K, Yamanaka S. Induction of pluripotent stem cells from mouse embryonic and adult fibroblast cultures by defined factors. Cell 2006;126:663-76. http://dx.doi.org/10.1016/j.cell.2006.07.024.

[52] El-Sayed A, Hoelker M, Rings F, Salilew D, Jennen D, Tholen E, et al. Large-scale transcriptional analysis of bovine embryo biopsies in relation to pregnancy success after transfer to recipients. Physiol Genomics 2006;28:84-96. http://dx.doi.org/10. 1152/physiolgenomics.00111.2006. 